\title{
Motor development of infants (6-12 months) with low birth weight
}

\author{
Vanessa Cristina Waetge Pires de Godoy ${ }^{*}$ (1), Fabiola Isabel Suano de Souza' (1), \\ Cintia Johnston ${ }^{2}$ (D), Maria Wany Louzada Strufaldi ${ }^{1}$
}

\section{SUMMARY}

OBJECTIVE: The aim of this study was to describe the motor development (MD) and growth of infants born with low birth weight (LBW) versus adequate birth weight (ABW) by using the Alberta Infant Motor Scale (AIMS).

METHODS: The cross-sectional study including LBW infants (aged 6-12 months) followed at an outpatient clinic from a University Hospital in Brazil and a group of infants of the same age with ABW. The variables were recorded as maternal, birth, and infant conditions. The infants were assessed for MD using the AIMS.

RESULTS: In total, 98 infants (38 LBW versus $60 \mathrm{ABW}$ ) were evaluated and no statistically significant differences were found in demographic characteristics and in the AIMS results. The AIMS results of the total sample were suspicious or abnormal MD in 44 (45\%) of total infants. Higher frequency of suspected or abnormal motor behavior was found in the age group between 9 and 12 (54.6\%) months. CONCLUSIONS: A frequency of $45 \%$ of suspected or abnormal behavior was observed in the evaluated infants, with a higher frequency of occurrence in those aged 9-12 months (54.6\%).

KEYWORDS: Infant, low birth weight. Motor skills.

\section{INTRODUCTION}

Low birth weight (LBW) is defined by the World Health Organization as birth weight of $<2.500 \mathrm{~g}$, regardless the gestational age (GA), including preterm newborns, those with intrauterine growth restriction or small for GA infants. LBW is considered a global public health problem and is associated with a series of functional consequences ${ }^{1,2}$.

In 2019, it was estimated 20.5 million live births with LBW, mostly (91\%) in low/middle income countries². In Latin America, the rate observed was $8.7 \%^{2}$. In Brazil approximately $8.5 \%$ of live births were born $\mathrm{LBW}^{3}$, and in Sáo Paulo it was $9.5 \%{ }^{3}$.

Children with LBW was at risk for growth, and motor developmental (MD) delays with a broad spectrum of alterations such as cognitive, behavioral, and learning disabilities ${ }^{4}$. Functional changes usually become more apparent over the years, resulting in difficulties in reading and writing in the school phase ${ }^{5}$.

In the first 5 years of life, the motor acquisition of child represents the integrity and functionality of other systems ${ }^{6}$. The early identification of possible MD delay, and timely intervention can lead to a better prognosis for children at risk for developmental disorders ${ }^{7}$.

The Alberta Infant Motor Scale (AIMS) is considered a dynamic assessment scale, as it describes the acquisitions achieved by the child and enables the analysis of the components necessary for the acquisition of certain skills. It emphasizes movement patterns and skills in different gravitational situations, as well as weight distribution, posture, and antigravity movement. It is a low cost and easy-to-apply instrument ${ }^{6,8}$.

\footnotetext{
1Universidade Federal de São Paulo, Escola Paulista de Medicina - São Paulo (SP), Brazil.

¿Universidade de São Paulo, Departamento de Pediatria - São Paulo (SP), Brazil.

*Corresponding author: van_godoy18@hotmail.com

Conflicts of interest: the authors declare there is no conflicts of interest. Funding: Fundação Coordenação de Aperfeiçoamento de Pessoal de Nível Superior. Received on December 10, 2020. Accepted on December 13, 2020.
} 
Although infants with LBW are at higher risk for growth and MD delay and developing short- and long-term diseases ${ }^{4}$, a few studies ${ }^{9-11}$ evaluated the MD in the first year of life applying AIMS. Thus, the main objective of this study was to evaluate the MD of infants aged 6-12 months with LBW by AIMS.

\section{METHODS}

This cross-sectional clinical trial included infants born with LBW (LBW Group) and healthy infants (aged between 6 and 12 months) of the same age and also born at term with adequate birth weight (ABW Group). The study was approved by the Ethics Committee (No. 1.904.715). Infants diagnosed with central or peripheral nervous system malformations, encephalopathy, congenital heart disease, genetic syndromes, or the Apgar score $<7$ in the fifth minute were excluded.

The variables were noted as follows: information about birth (i.e., type, clinical condition of mother, complications, birth GA, birth weight, height, and head circumference), length of stay in the nursery and neonatal complications, the Apgar score, resuscitation procedures, and maternal conditions (e.g., age, parity, chronic diseases, complications during pregnancy, tobacco/alcohol/drug use, socioeconomic status, and education).

Gestational age and birth weight were used to classify the newborn as appropriate for GA (AGA), small for GA (SGA), or large for GA (LGA) ${ }^{12}$. For MD and nutritional status assessment, all premature infants (GA $\leq 37$ weeks) had their GA corrected to 40 weeks ${ }^{2}$. For anthropometry, at the time of MD evaluation, weight $(\mathrm{g})$, length $(\mathrm{cm})$, and head circumference $(\mathrm{cm})$ measurements were obtained ${ }^{13}$. The indicators shown as $Z$-score for age were weight/age, height/age, body mass index (BMI), and head circumference/age ${ }^{13}$.

Environment/routines of the infant were as follows: use of a walker, habit of placing the child in prone position, and attending in a day care during the period of the evaluation. MD evaluation was performed by using the $\mathrm{AIMS}^{8}$ applied by two trained physiotherapists. The total score was converted into a percentile curve, and the MD ratings of infant were included ${ }^{8}$ as follows:

1. Normal or typical motor performance when $>\mathrm{p} 25$ on the scale percentile curve;

2. Suspicious motor performance between $\mathrm{p} 5$ and $\mathrm{p} 25$; and

3. Abnormal motor performance when $<\mathrm{p} 5$.

At the moment of the MD evaluation the infant was positioned in a firm surface, and specific stimuli were provided to apply the tests according to the age range to be evaluated, manipulating the child only when necessary ${ }^{8}$.

All evaluations were recorded by filming, with the purpose of performing the disagreement/agreement analysis between the two physiotherapists. In case of disagreement, a third trained physiotherapist analyzed the videos. The children were worn only with diapers, and the evaluations were performed between feedings, as long as they were active and awake (Brazelton Scale at level 4 or 5$)^{14}$.

\section{Statistical analysis}

The data were recorded in an Excel spreadsheet $\left(\mathrm{Office}^{\circledR}\right)$ and analyzed using the Statistical Package for Social Sciences for Windows (SPSS, Chicago, IL, USA) $25.0\left(\right.$ IBM $\left.^{\circledR}\right)$. Qualitative variables were presented as absolute numbers and percentages, compared by using the Pearson's chi-square test. The normality of continuous variables was assessed using the Shapiro-Wilk test. Those that presented parametric distribution were presented as mean \pm standard deviation, compared by using the Student's $t$-test. Variables with nonparametric distribution were presented as median and $25-75 \%$ interquartile range and compared using the Mann-Whitney $U$ test. The variables were considered statistically significant when $\mathrm{p} \leq 0.05$.

\section{RESULTS}

In this study, 69 eligible infants were attended at the LBW outpatient clinic, and 17 infants were excluded due to congenital malformations and 14 due to loss of follow-up, resulting in the inclusion of 38 infants with LBW, and 60 with ABW.

The maternal sociodemographic and gestational characteristics of infants can be observed in Tables 1 and 2. In LBW group, the mothers had a higher percentage of complications during pregnancy $(87 \%$ versus $45 \%$; $<<0.001)$, the most frequent were infectious and specific pregnancy hypertensive disease (Table 1).

Among the evaluated infants, the mean birth weight of LBW

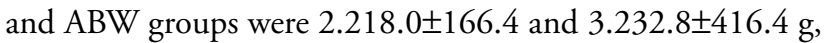
respectively $(\mathrm{p}<0.001)$. The LBW group had a higher frequency of SGA infants ( $42 \%$ versus $10 \%$; $<<0.001$ ), as well as neonatal complications ( $57 \%$ versus $12 \%$; $\mathrm{p}<0.001$ ) (Table 2 ).

The $66 \%$ of LBW infants were born premature (GA: $35.5 \pm 1.7$ weeks). The average length of stay after birth was $<10(8.9 \pm 6.8)$ days. Four newborns from the LBW group (11\%) remained in the intensive care unit, but the hospitalization time was $<24 \mathrm{~h}$.

At the time of the AIMS evaluation, the mean real and corrected age of infants were 273.5 \pm 77.2 days in LBW group versus 215.6 \pm 60.7 days in $A B W$ group. It was observed that $14(37 \%)$ of the LBW group received breast milk versus 49 $(82 \%)$ in ABW group $(\mathrm{p}<0.001)$. No statistical differences were observed between the groups concerning their nutritional conditions. There was no correlation between MD assessment and nutritional status in the groups. 
Table 1. Maternal sociodemographic and gestational characteristics of infants with low birth weight and adequate birth weight, 2020.

\begin{tabular}{|c|c|c|c|c|c|}
\hline \multirow{2}{*}{ Variables } & \multicolumn{2}{|c|}{ LBW $(n=38)$} & \multicolumn{2}{|c|}{$A B W(n=60)$} & \multirow{2}{*}{ p-value } \\
\hline & $n$ & $\%$ & $\mathrm{n}$ & $\%$ & \\
\hline Maternal age (years)* & $29.9 \pm 6.8$ & & $26.7 \pm 6.4$ & & $0.015^{+}$ \\
\hline \multicolumn{6}{|l|}{ Maternal schooling } \\
\hline Elementary school & 11 & 28.9 & 23 & 38.5 & \multirow{3}{*}{$0.219^{\ddagger}$} \\
\hline High school & 20 & 52.6 & 35 & 58.3 & \\
\hline University education & 7 & 18.4 & 2 & 3.2 & \\
\hline \multicolumn{6}{|l|}{ ABEP } \\
\hline A & 0 & 0.0 & 0 & 0.0 & \multirow{6}{*}{$0.258^{\ddagger}$} \\
\hline B & 3 & 7.9 & 1 & 1.7 & \\
\hline B1 & 12 & 31.6 & 10 & 16.7 & \\
\hline $\mathrm{C} 1$ & 16 & 42.1 & 35 & 58.3 & \\
\hline $\mathrm{C} 2$ & 6 & 15.8 & 11 & 18.3 & \\
\hline D-E & 1 & 2.6 & 3 & 5.0 & \\
\hline Prenatal initiation (months)* & $1.0 \pm 0.16$ & & $1.13 \pm 0.34$ & & $0.036^{+}$ \\
\hline Number of pregnancies* & $1.6 \pm 1.3$ & & $2.2 \pm 0.9$ & & $0.024^{+}$ \\
\hline \multicolumn{6}{|l|}{ Smoking } \\
\hline Yes & 1 & 2.6 & 2 & 3.3 & \multirow{2}{*}{$0.649^{\ddagger}$} \\
\hline No & 37 & 97.4 & 58 & 96.7 & \\
\hline \multicolumn{6}{|l|}{ Alcoholism/drugs } \\
\hline Yes & 1 & 2.6 & 2 & 3.3 & \multirow{2}{*}{$0.649^{\ddagger}$} \\
\hline No & 37 & 97.4 & 58 & 96.7 & \\
\hline \multicolumn{6}{|l|}{ Gestational complications } \\
\hline Yes & 33 & 86.8 & 27 & 45.0 & \multirow{2}{*}{$<0.001^{\ddagger}$} \\
\hline No & 5 & 13.2 & 33 & 55.0 & \\
\hline \multicolumn{6}{|l|}{ Type of complications } \\
\hline Cardiovascular & 13 & 34.2 & 3 & 5.0 & \multirow{8}{*}{$<0.001^{+}$} \\
\hline Respiratory & 1 & 2.6 & 0 & 0 & \\
\hline Genitourinary & 5 & 13.1 & 2 & 3.3 & \\
\hline Hematological & 4 & 10.5 & 4 & 6.7 & \\
\hline Infectious & 15 & 42.8 & 14 & 23.3 & \\
\hline Metabolic & 4 & 10.5 & 0 & 0 & \\
\hline Neurological & 1 & 2.6 & 0 & 0 & \\
\hline Others & 11 & 28.9 & 4 & 6.7 & \\
\hline \multicolumn{6}{|l|}{ Type of delivery } \\
\hline Vaginal & 4 & 10.0 & 34 & 56.7 & \multirow{2}{*}{$<0.001^{\ddagger}$} \\
\hline Cesarean section & 34 & 89.5 & 26 & 43.3 & \\
\hline
\end{tabular}

LBW: low birth weight; ABW: adequate birth weight; n: number; \%: absolute percentage; ABEP: Associação Brasileira de Empresas de Pesquisa; *data in averaged \pm standard deviation of the mean; 'student's $t$-test significance level; ₹Chi-square test significance level. 
Table 2. Conditions at birth and anthropometry at the date of motor assessment of infants with low birth weight and adequate birth weight, 2020.

\begin{tabular}{|c|c|c|c|c|c|}
\hline \multirow{2}{*}{ Variables } & \multicolumn{2}{|c|}{ LBW $(n=38)$} & \multicolumn{2}{|c|}{ ABW $(n=60)$} & \multirow{2}{*}{ p-value } \\
\hline & $\mathrm{n}$ & $\%$ & $n$ & $\%$ & \\
\hline \multicolumn{6}{|l|}{ Gender } \\
\hline Male & 19 & 50.0 & 34 & 56.7 & \multirow{2}{*}{$0.540^{+}$} \\
\hline Female & 19 & 50.0 & 26 & 43.3 & \\
\hline Birth weight $(g)^{*}$ & $2218 \pm 166.4$ & & $3232.8 \pm 416.4$ & & $<0.001^{\ddagger}$ \\
\hline \multicolumn{6}{|c|}{ Adequate for gestational age } \\
\hline SGA & 16 & 42.1 & 6 & 10.0 & \multirow{3}{*}{$<0.001^{\dagger}$} \\
\hline AGA & 22 & 57.9 & 42 & 70.0 & \\
\hline LGA & 0 & 0.0 & 12 & 20.0 & \\
\hline \multicolumn{6}{|l|}{ Neonatal complications } \\
\hline Yes & 21 & 57.5 & 7 & 11.7 & \multirow{2}{*}{$<0.001^{\dagger}$} \\
\hline No & 17 & 42.5 & 53 & 88.3 & \\
\hline
\end{tabular}

\begin{tabular}{|c|c|c|c|c|c|}
\hline \multicolumn{6}{|l|}{ Type of complications } \\
\hline Infectious & 4 & 11.4 & 0 & 0 & \multirow{5}{*}{$<0.001^{\dagger}$} \\
\hline Respiratory & 12 & 31.6 & 0 & 0 & \\
\hline Metabolic & 5 & 13.1 & 0 & 0 & \\
\hline Icterus & 7 & 18.4 & 8 & 13.3 & \\
\hline Others & 5 & 13.1 & 0 & 0 & \\
\hline \multicolumn{6}{|l|}{ Z-score height } \\
\hline Short stature & 7 & 18.4 & 2 & 3.4 & \multirow{2}{*}{$0.026^{+}$} \\
\hline Adequate height & 31 & 81.6 & 57 & 96.6 & \\
\hline \multicolumn{6}{|l|}{ Z-score BMI } \\
\hline Thinness & 1 & 2.6 & 1 & 1.7 & \multirow{3}{*}{$0.897^{+}$} \\
\hline Eutrophic & 31 & 81.6 & 48 & 80 & \\
\hline Overweight/obesity & 6 & 15.8 & 11 & 18.3 & \\
\hline \multicolumn{6}{|l|}{ Z-score HP } \\
\hline Adequate & 38 & 100 & 60 & 100 & \\
\hline
\end{tabular}

LBW: low birth weight; ABW: adequate birth weight; n: number; \%:absolute percentage; SGA: small for gestational age; AGA: adequate for gestational age; LGA: large for gestational age; BMI: body mass index; HP: head perimeter; * data in averaged \pm standard deviation of the mean; ${ }^{\dagger C h i-s q u a r e ~ t e s t ~}$ significance level; :Student's t-test significance level.

Through the interview with parents/legal guardians of the infants, it was obtained that $82 \%$ of the LBW group and $90 \%$ of the ABW group were under the parental care and did not attend at a day care.

The AIMS results observed were suspicious or abnormal in $18(47 \%)$ in the LBW group versus $26(43 \%)$ in the ABW group $(\mathrm{p}=0.522)$. There were no statistically significant difference between the groups, regarding total score and test components (Table 3). However, the median score of the seated position was lower in the LBW group versus the $A B W$ group [i.e., $7.0(3.0-11.2)$ versus 9.5 $(5.0-12.0)](\mathrm{p}=0.087)$.

It was observed that at the age of 6-9 months, $44.4 \%$ of the infants in the LBW group had suspicious or abnor$\mathrm{mal} /$ atypical motor behavior, and in the ABW group the frequency was $37.2 \%$. Infants aged 9-12 months had a higher frequency of suspicious or abnormal behavior (i.e., 54.6\% in the LBW group). 
Table 3. Total and component score of Alberta Infant Motor Scale in children with low birth weight and adequate birth weight, 2020.

\begin{tabular}{|c|c|c|c|}
\hline AIMS & LBW $(n=38)$ & $A B W(n=60)$ & $p$-value \\
\hline Total score & $27.5(19.0 ; 43.0)$ & $31.5(22.2 ; 42.7)$ & $0.233^{*}$ \\
\hline \multicolumn{4}{|l|}{ Classification } \\
\hline Normal & $20(52.6)$ & $34(56.7)$ & \multirow{3}{*}{$0.522^{+}$} \\
\hline Suspicious & $12(31.6)$ & $21(35.0)$ & \\
\hline Abnormal & $6(15.8)$ & $5(8.3)$ & \\
\hline \multicolumn{4}{|l|}{ Prone } \\
\hline Score & $10.5(7.0,17.0)$ & $12.0(7.0,17.7)$ & $0.483^{*}$ \\
\hline \multicolumn{4}{|l|}{ Supine } \\
\hline Score & $8.0(6.0,9.0)$ & $7.5(6.0,9.0)$ & $0.888 *$ \\
\hline \multicolumn{4}{|l|}{ Seated } \\
\hline Score & $7.0(3.0,11.2)$ & $9.5(5.0,12.0)$ & 0.087 * \\
\hline \multicolumn{4}{|l|}{ Standing } \\
\hline Score & $3.0(2.7,6.3)$ & $3.0(3.0,5.0)$ & $0.553 *$ \\
\hline
\end{tabular}

AIS: Alberta Infant Motor Scale; LBW: low birth weight; ABW: adequate birth weight; n: number, and data expressed as median and interquartile range; *Mann-Whitney $U$ test significance level; ${ }^{+}$Chi-square test significance level.

\section{DISCUSSION}

This study observed that MD of infants with LBW (i.e., between 6 and 12 months of corrected age) assessed by AIMS was similar to the group of healthy infants born at term with ABW in São Paulo, Brazil. In both groups, there was a high percentage of suspicious or abnormal MD performance.

There are several standardized tests and scales that help identifying children at risk for MD delay, which can be used for screening and diagnosis and for therapeutic planning if any abnormality is detected ${ }^{15}$. Choosing the best test for assessing MD in infants remains a challenge ${ }^{15,16}$. The detection of changes in MD in the first year of life has a high predictive value for the medium and the long-term global developmental changes ${ }^{16}$.

During the evaluation of the MD in children from 1 month to 2 years old, it was identified that the motor domain was the first to present a delay, starting around 10 months of age, followed by the language domain ${ }^{17}$. Those minor deviations in MD between 9 and 15 weeks of age are associated with receptive and expressive language delay at 1.5 and 2.5 years, concluding that motor function delays may precede delays in other domains ${ }^{17,18}$.

In this study, the results of MD assessment by AIMS were similar in both groups. It is noteworthy that the characteristics that represent risk factors for MD delay such as the Apgar score, socioeconomic status, and maternal education were similar in all evaluated infants. In both groups, more than $40 \%$ of infants were classified by AIMS as having suspicious or abnormal MD.
Some studies ${ }^{19-21}$ suggest that the poorer performance of Brazilian children could be related to the fact that instruments suffer interference from cross-cultural adaptation. Other possible elements involved could be the distinct socioeconomic, ethnic, and cultural factors and the greater daily exposure of Brazilian children to biological and environmental risk factors ${ }^{19,21}$.

The maternal practices, such as the preference for the supine position due to the concern with the sudden infant death syndrome, could be another factor associated with the observed differences ${ }^{18}$. The lack of habit of Brazilian parents in leaving their children in prone position, even when they are awake, may be a risk factor ${ }^{22}$. Another study ${ }^{23}$ verified the influence of maternal practices on the MD of healthy infants between 6 and 12 months of age, suggesting that practices that encourage the adoption of four-support posture and the use of the floor have a positive influence in the MD.

In this study, when infants were stratified in trimesters of age, there was a higher percentage of suspected or abnormal MD between 9 and 12 months (54.6\%) than between 6 and 9 months (44.4\%). These results are similar to other studies $^{24}$ using the AIMS and concluded that in the first 3 months and from 13 months of life, the AIMS curve is not as sensitive for detecting MD delays between 4 and 12 months of age.

Independent sitting is a posture that a child acquires between 6th and 7 th month of life that is not a locomotion posture such as crawling and walking, but it is a stabilizing 
posture necessary for the development of balance, coordination, and motor control, requiring static and dynamic muscle control, which may occur later in children with $\mathrm{LBW}^{22}$. The acquisition of postures in MD in the early years of life is influenced by the environment of the child and by the sociocultural context ${ }^{19-23}$.

This study has some limitations. It is a cross-sectional study including a convenience sample. The validation proposed of a version of AIMS for the Brazilian population not yet normative for the analysis of motor performance in this popula$\operatorname{tion}^{20}$. Previous studies ${ }^{19-21}$ observed that the MD of Brazilian children were lower than those observed in Canada, except at 18 months. The reference values for AIMS are still the values determined by the Canadian study ${ }^{16-21}$.

\section{CONCLUSIONS}

The motor development of LBW infants assessed by AIMS was similar to that of ABW infants, and approximately $60 \%$ of the sample was of premature newborns. A frequency of $45 \%$ of suspected or abnormal behavior was observed in the evaluated infants, with a higher frequency of occurrence in those aged 9-12 (54.6\%) months.

\section{AUTHORS' CONTRIBUTIONS}

VCWPG: Investigation, Methodology, Project administration, Writing - original draft. FISS: Formal analysis, Statistical analysis, Writing - review \& editing. CJ: Methodology, Validation. MWLS: Formal analysis, Methodology, Validation, Writing - review \& editing.

\section{REFERENCES}

1. Organização das Nações Unidas. Declaração mundial sobre a sobrevivência, a proteção e o desenvolvimento da criança nos anos 90. Nova lorque: Organização das Nações Unidas; 1990

2. Blencowe $H$, Krasevec J, Onis M, Black RE, An X, Stevens GA, et al. National, regional, and worldwide estimates of low birthweight in 2015, with trends from 2000: a systematic analysis. Lancet Glob Health. 2019; 7e(7):e849-e860. https:// doi.org/10.1016/S2214-109X(18)30565-5

3. DATASUS. Tecnologia da Informação a Serviço do SUS. Nascidos vivos São Paulo. [cited on 2019 Jun 03]. Available from: http:// tabnet.datasus.gov.br/cgi/tabcgi.exe?sinasc/cnv/nvsp.def

4. Taine M, Charles MA, Beltrand J, Rozé JC, Léger J, Botton $J$, et al. Early postnatal growth and neurodevelopment in children born moderately preterm or small for gestational age at term: a systematic review. Paediatr Perinat Epidemiol. 2018;32(26):8-28. https://doi.org/10.1111/ppe.12468

5. Starnberg J, Norman M, Westrup B, Domellöf M, Berglund SK. Lower cognitive test scores at age 7 in children born with marginally low birth weight. Pediatr Res. 2018;83(6):1129-35. https://doi.org/10.1038/pr.2018.35

6. Sacanni R. Trajetória motora de crianças brasileiras de 0 a 18 meses de idade: normatização da Alberta Infant Motor Scale para aplicação clínica e científica no Brasil. Rio Grande do Sul [tese]. Porto Alegre: Escola Superior de Educação Física, Universidade Federal do Rio Grande do Sul, 2013.

7. Boivin MJ, Kakooza AM, Warf BC, Davidson LL, Grigorenko EL. Reducing neurodevelopmental disorders and disability through research and interventions. Nature. 2015;527(7578):S155-60. https://doi.org/10.1038/nature16029

8. Piper MC, Darrah J. Motor assessment of the developing infant. Alberta: Saunders; 1994.

9. Ribeiro CC, Pachelli MRO, Amaral NCO, Lamônica DAC. Development skills of children born premature with low and very low birth weight. Codas. 2017;29(1):e20160058. https:// doi.org/10.1590/2317-1782/20162016058
10. Formiga CKMR, Cezar MEN, Linhares MBM. Avaliação longitudinal do desenvolvimento motor e da habilidade de sentar em crianças nascidas prematuras. Fisioter Pesqui. 2010;17(2):102-7. https://doi.org/10.1590/S180929502010000200002

11. Sampaio TF, Nogueira KPA, Pontes TB, Toledo AM Comportamento motor de lactentes prematuros de baixo peso e muito baixo peso ao nascer. Fisioter Pesqui. 2015;22(3):25360. https://doi.org/10.590/1809-2950/13533022032015

12. Papageorghiou AT, Ohuma EO, Altman DG, Todros T, Ismail LC, Lambert A, et al. International standards for fetal growth based on serial ultrasound measurements: the Fetal Growth Longitudinal Study of the INTERGROWTH-21st project. Lancet. 2014;384(9946):869-79. https://doi.org/10.1016/ S0140-6736(14)61490-2

13. World Health Organization. WHO child growth standards: length/height-for-age, weight-for-age, weight-for-length, weight-for-height and body mass index-for-age: methods and development. Geneva: World Health Organization; 2006.

14. Vignochi C, Teixeira PP., Nader SS. Effect of aquatic physical therapy on pain and state of sleep and wakefulness among stable preterm newborns in neonatal intensive care units. Rev Bras Fisioter. 2010;14(3):214-20. PMID: 20730365

15. Blauw-Hospers $C H$, de Graaf-Peters VB, Dirks T, Bos AF, HaddersAlgra M. Does early intervention in infants at high risk for a developmental motor disorder improve motor and cognitive development? Neurosci Biobehav Rev. 2007;31(8):1201-12. https://doi.org/10.1016/j.neubiorev.2007.04.010

16. Valentini NC, Saccani R. Brazilian validation of the Alberta Infant Motor Scale. Phys Ther. 2012;92(3):440-7. https://doi. org/10.2522/ptj.20110036

17. Nishimura T, Takei N, Tsuchiya KJ, Asano R, Mori N. Identification of neurodevelopmental trajectories in infancy and of risk factors affecting deviant development: a longitudinal birth cohort study. Int J Epidemiol. 2016;45(2):543-53. https://doi. org/10.1093/ije/dyv363 
18. van Batenburg-Eddes T, Henrichs J, Schenk JJ, Sincer I, de Groot L, Hofman A, et al. Early infant neuromotor assessment is associated with language and nonverbal cognitive function in toddlers: the Generation R Study. J Dev Behav Pediatr. 2013;34(5):326-34. https://doi.org/10.1097/ DBP.0b013e3182961e80

19. Gontijo APB, Magalhães LC, Guerra MQF. Assessing gross motor development of Brazilian infants. Pediatr Phys Ther. 2014;26(1):48-55. https://doi.org/10.1097/ PEP.0000000000000014

20. Saccani R, Valentini NC. Reference curves for the Brazilian Alberta Infant Motor Scale: percentiles for clinical description and follow-up over time. J Pediatr (Rio J) 2012;88(1):40.

21. Saccani R, Valentini NC. Análise transcultural do desenvolvimento motor de crianças brasileiras, gregas e canadenses avaliadas com a Alberta Infant Motor Scale. Rev Paul Pediatr. 2013;31(3):350-8. https://doi.org/10.1590/S0103-05822013000300012

22. Formiga CKMR, Pedrazzani ES, Tudella E. Desenvolvimento motor de lactentes pre-termo participantes de um programa de intervenção fisioterapêutica precoce. Rev Bras Fisioter. 2004;8(3):239-45.

23. Silva PL, Santos DCC, Gonçalves VMG. Influência de práticas maternas no desenvolvimento motor de lactentes do $6^{\circ}$ ao $12^{\circ}$ meses de vida. Braz J Phys Ther. 2006;10(2):225-31. https:// doi.org/10.1590/S1413-35552006000200014

24. Campbell SK, Kolobe THA, Wright BD, Linacre JM. Validity of the test of infant motor performance for prediction of 69- and 12-month scores on the Alberta Infant Motor Scale. Dev Med Child Neurol. 2002;44(4):263-72. https://doi. org/10.1017/s0012162201002043 